\title{
Teorias da comunicação, transferência do conhecimento e implicações na subserviência dos sujeitos nas organizações
}

Theories of communication, transfer of knowledge and implications on the subservience of subjects in organizations

Teorías de la comunicación, transferencia del conocimiento e implicaciones sobre la subordinación de los sujetos en las organizaciones

Fábia Pereira Lima

- Doutora em Ciências da Comunicação pela Universidade de São Paulo (USP)

- Mestre em Comunicação Social: Interações Midiáticas pela Pontifícia Universidade Católica de Minas Gerais (PUC Minas)

- Especialista em Gestão Estratégica de Marketing pela PUC Minas

- Graduada em Comunicação Social com habilitação em Relações Públicas pela PUC Minas

- Professora adjunta do Departamento de Comunicação Social da Universidade Federal de Minas Gerais (UFMG)

- Integrante dos Grupos de Pesquisa Comunicação, Mobilização Social e Opinião Pública - Mobiliza (UFMG) e Comunicação no Contexto Organizacional: Aspectos Teórico-Conceituais - Dialorg (PUC Minas)

- E-mail: fabialima@ufmg.br 


\section{Resumo}

Este artigo reflete sobre estudos de transferência de conhecimento nas organizações, denunciando como certas concepções podem encobrir postulados que coisificam o homem e abrem caminho para a naturalização de correntes teóricas e práticas de subserviência ao modelo produtivo capitalista, que são reproduzidas e integram a cultura organizacional. 0 artigo defende que os estudos de comunicação organizacional podem e devem contribuir para desconstruir premissas que integrem a sutil rede de violências simbólicas que pautam relações sociais, objetos de pesquisa e práticas organizacionais.

\section{PALAVRAS-CHAVE: TEORIAS DA COMUNICAÇÃO • TRANSFERÊNCIA DO CONHECIMENTO • GESTÃO DO CONHECIMENTO • ANÁLISE CRÍTICA DO} DISCURSO.

\section{Abstract}

This article reflects on studies of knowledge transfer in organizations denouncing how certain conceptions can cover up postulates that restrain man and open the way for the naturalization of theoretical currents and practices of subservience to the capitalist productive model that are reproduced and integrate the organizational culture. He argues that organizational communication studies can and should contribute to the deconstruction of premises that integrate the subtle network of symbolic violence that guide social relations, research objects and organizational practices.

KEYWORDS: THEORIES OF COMMUNICATION • KNOWLEDGE TRANSFER • KNOWLEDGE MANAGEMENT • CRITICAL DISCOURSE ANALYSIS.

\section{Resumen}

Este artículo refleja sobre estudios de transferencia de conocimiento en las organizaciones denunciando cómo ciertas concepciones pueden encubrir postulados que coser el hombre y abrir el camino para la naturalización de corrientes teóricas y prácticas de subordinación al modelo productivo capitalista que se reproducen e integran la cultura organizacional. Defiende que los estudios de comunicación organizacional pueden y deben contribuir a deconstruir premisas que integren la sutil red de violencias simbólicas que pautan relaciones sociales, objetos de investigación y prácticas organizacionales. 


\section{INTRODUÇÃO}

0 s estudos sobre transferência do conhecimento nas organizações têm constituído relevante pauta de trabalhos nas escolas de gestão, especialmente, a partir dos anos 1990, quando o conhecimento passou a ser considerado um ativo organizacional intangível altamente estratégico. Nesse sentido, são empreendidos esforços para identificar fatores relevantes que tornem eficazes os processos de transferência do conhecimento de modo a garantir um diferencial competitivo para as organizações. Tal entendimento se liga à ideia de que é preciso instaurar processos de aprendizagem organizacional para que os saberes produzidos pelos trabalhadores não se percam neles mesmos, mas, ao contrário, sejam compartilhados com os demais atores organizacionais de interesse, fazendo o coletivo ganhar distintividade precisamente pelo conhecimento comum acumulado.

A principal filiação dos estudos sobre transferência do conhecimento nas organizações são as pesquisas na área da ciência da informação. São, portanto, herdeiros de trabalhos que focam no estudo da transferência de informação e de dados, não conseguindo distinguir conceitualmente, de modo suficientemente consensual, tais definições. 0 que se pretende argumentar neste artigo é que o desenvolvimento das teorias da comunicação pode contribuir para desconstruir o entendimento de que o conhecimento é algo possível de ser transferido. Ou seja, questionar noções que, de forma silente, reificam o ser humano e suas relações - principalmente a relação do ser humano com o trabalho e como ele se entende nas organizações, integrando, de modo subserviente, o modelo produtivo capitalista contemporâneo.

Sem a pretensão de promover uma narrativa histórica e tampouco linear ou evolucionária dos estudos da comunicação, resgatando suas principais perspectivas paradigmáticas, optou-se por enfatizar duas reconhecidas escolas teóricas que, em estudos como os de Winkin (1998) e Quéré (2018), parecem evidenciar mais nitidamente contrastes conceituais fundamentais na própria conformação da comunicação como objeto de estudo - e trazendo consequências nas pesquisas alinhadas a perspectivas distintas. Para conduzir a reflexão, que se configura como um contraponto à noção de que o conhecimento é algo que pode ser transferido, assumimos como matriz teórico-metodológica a análise crítica do discurso, a partir dos estudos de Fairclough (2001, 2003). Trata-se, como se verá, da adoção de uma abordagem que transcende os limites dos métodos estritos e se revela mais como um arcabouço teórico-reflexivo, a partir do qual as perspectivas paradigmáticas acionadas podem ser problematizadas.

\section{REFERENCIAL TEÓRICO}

\section{Transferência da informação, de dados e do conhecimento: da ciência da informação e da computação aos estudos organizacionais}

Os estudos referentes à transferência da informação dizem respeito ao modo com que os grupos e as instituições organizam a informação, através de procedimentos seletivos que regulam sua geração, transmissão, distribuição e uso. Nesse processo, chama atenção o efeito globalizador dos mercados e o desenvolvimento das tecnologias de informação, que impactam o desenvolvimento da produção do conhecimento na área das ciências da informação e tornam imperativo adotar como premissa epistemológica a questão do máximo alcance e da uniformidade linguística ou das lógicas de uso da informação (Gomez, 1993). Segundo Gomez (1993, p. 218), 
Percebe-se, portanto, que o avanço tecnológico possibilitou o tratamento da informação em grandes escalas e em novas perspectivas espaço-temporais, impelindo os pesquisadores a alinharem o conceito de informação ao de dado. Também na linguagem da computação, dado aparece como input integrante da simbiótica relação homem-máquina que marca 0 contemporâneo. É dessa forma que percebemos que os estudos organizacionais, tomados em sua generalidade, apropriamse da noção de transferência do conhecimento: tomando conhecimento como algo, se não equivalente, pelo menos similar à informação ou ao dado, uma coisa que pode ser transmitida de um emissor $\mathrm{A}$ até um receptor B! .

No entanto, não é possível desconsiderar os esforços de vários autores que buscaram marcar a diferença existente entre dado, informação e conhecimento, como Drucker (1988), Dutta (1997) e Marshall (1997). Destacamos, nessa linha, o trabalho de Davenport e Prusak (2003), dois dos mais reconhecidos pesquisadores da área de tecnologia da informação e gestão do conhecimento, para quem, embora conhecimento não possa ser considerado nem dado nem informação, as diferenças entre esses termos estão somente em uma questão de gradação. Para os autores, enquanto "dados são um conjunto de fatos distintos e objetivos, relativos a eventos [que], num contexto organizacional, [...] são utilitariamente descritos como registros estruturados de transações" (Davenport; Prusak, 2003, p. 4), informação são os dados com significados que, assim, "fazem a diferença" no sentido tanto de dar uma forma aos dados, constituindo uma mensagem, quanto de dar forma ao receptor, quando ele the atribui significado. Segundo os autores,

dados tornam-se informação quando o seu criador thes acrescenta significado. Transformamos dados em informação agregando valor de diversas maneiras. Consideremos vários métodos importantes, todos eles começando com a letra C: Contextualização: sabemos qual a finalidade dos dados coletados. Categorização: conhecemos as unidades de análise ou os componentes essenciais dos dados. Cálculo: os dados podem ser analisados matemática ou estatisticamente. Correção: os erros são eliminados dos dados. Condensação: os dados podem ser resumidos para uma forma mais concisa. Observe que os computadores podem ajudar a agregar tais valores e transformar dados em informação, porém quase nunca eles ajudam na parte de contexto, e os seres humanos geralmente precisam agir nas partes de categorização, cálculo e condensação. (Davenport; Prusak, 2003, p. 5)

Assim, numa perspectiva gradativa ou evolucionária dos conceitos - e funcional, no que concerne ao ambiente organizacional -, os autores definem o conhecimento como o produto de experiências, valores e informações contextualizadas que, retroativamente, criam as bases para os sujeitos lidarem com novas experiências e informações.

Nas conceituações apresentadas, fica claro o entendimento de que a produção de conhecimento é algo da ordem do humano, a partir de sua capacidade de significar informações. Contudo, percebe-se limitação na teorização proposta, por conta da fragilidade conceitual no que se refere aos processos de produção de sentido que embasam a comunicação. Dessa forma, as reflexões dos autores resvalam para a ideia de conhecimento como propriedade humana, que pode ser transferida ou transmitida a outras pessoas ou imbuída em coisas - e, mais, sem perder de vista os objetivos organizacionais com os quais possa contribuir. Isso fica claro quando os autores apontam que:

Ele [o conhecimento] tem origem e é aplicado na mente dos conhecedores. Nas organizações, ele costuma estar embutido não só em documentos ou repositórios, mas também em rotinas, processos, práticas e normas organizacionais. [...] 0 conhecimento existe dentro das pessoas, faz parte da complexidade e imprevisibilidade humanas. [...] 0 conhecimento pode e deve ser avaliado pelas decisões ou tomadas de ação às quais ele leva. Um conhecimento melhor pode levar, por exemplo, a eficiência mensurável em desenvolvimento de produtos e na sua produção. Podemos usá-lo para tomar decisões mais acertadas com relação a estratégia, concorrentes, clientes, canais de distribuição e ciclos de vida de produto e serviço. (Davenport; Prusak, 2003, p. 6)

1 Há de se ressalvar que a corrente dos estudos organizacionais críticos tem se configurado como contraponto a essa perspectiva transmissiva da comunicação, distinguindose das abordagens clássicas do marketing e das ciências gerenciais. 
Sobre a relação entre informação e conhecimento, vale ainda destacar o trabalho de Nonaka e Takeuchi (1997), citados por Alvarenga Neto (2002), que aponta duas perspectivas nos estudos da informação: a informação sintática, tratada por seu volume (teoria matemática de Shannon e Weaver), e a informação semântica, carregada de significado - sendo essa última a que os autores consideram em sua teoria de criação de conhecimento. No entanto, apesar de reconhecerem que informação e conhecimento têm alguma relação com sistemas de significado, capacidade inerentemente humana, defendem a possibilidade de transmissão do conhecimento:

Nonaka \& Takeuchi afirmam que o conhecimento explícito ou codificado é aquele que se refere ao conhecimento transmissível através da linguagem sistemática e formal. Uma outra importante contribuição desses autores é a visão ontológica de que 0 conhecimento só existe, reside é criado por indivíduos, uma tautologia para afirmar que uma organização não pode criar conhecimento sem indivíduos. (Nonaka; Takeuchi, 1997 apud Alvarenga Neto, 2002, p. 39)

Nos estudos de Teoria Geral da Administração, as abordagens teóricas relacionadas ao conhecimento, ao aprendizado organizacional e às competências essenciais na gestão estratégica datam dos anos 1980 (Chiavenato, 2010). Tais estudos analisam o comportamento humano nas organizações e as técnicas para torná-las mais eficientes, visando criar vantagem competitiva sustentável. Pressupõe-se que a denominada Gestão do Conhecimento (GC) crie um diferencial valioso para as organizações, posto que o conhecimento é um ativo intangível de difícil imitação, enraizado nas pessoas, e não nos recursos físicos - esses, sim, facilmente imitáveis pelos concorrentes (Quinn; Baruch; Zien, 1997).

Para problematizar a possibilidade de transferência ou transmissão do conhecimento, propomos um resgate das teorias da comunicação, contrapondo o modelo informacional e transmissivo ao praxeológico e interacional. Visamos trazer elementos que subsidiem uma análise que, partindo de uma reflexão epistemológica, evidencie implicações de ordem prática na subserviência dos sujeitos a um modelo produtivo, nas organizações.

\section{As teorias da comunicação: do modelo informacional ao praxeológico}

As ciências humanas desenvolveram-se, desde a segunda metade do século XIX, segundo a concepção positivista de construção do saber científico, até então empregada no campo das ciências naturais. Almejava-se alcançar, no estudo das ciências humanas e sociais, as mesmas condições de neutralidade científica (com um domínio absoluto do pesquisador sobre seu objeto de estudo) e uma perspectiva de segmentação do saber, a partir de uma visão fragmentada, mecanicista e causal da realidade. Mas, ao tomar o ser humano (e suas relações, que constituem a sociedade) como objeto de estudo, as ciências humanas e sociais colocaram em xeque os limites do pensamento positivista. Elas têm contribuído para uma redefinição do fazer científico, com uma abordagem que privilegia aspectos como a complexidade dos fatos sociais e a contribuição dos diversos saberes na produção desse conhecimento (Laville; Dionne, 1999).

Foi na esteira do positivismo que surgiram os primeiros estudos no campo da comunicação. Em resposta à emergência e consolidação dos meios de comunicação de massa, no início do século XX, a produção acadêmica sobre o tema ganha impulso, sobretudo, a partir dos estudos desenvolvidos no âmbito do chamado Mass Communication Research. Focadas principalmente na reflexão sobre as funções e os efeitos da mídia, essas pesquisas pioneiras buscavam entender o papel desempenhado pela mídia em uma sociedade que passava por profundas transformações, como a consolidação do capitalismo e das democracias modernas, além da ocorrência das duas Grandes Guerras. Ao mesmo tempo, esses estudos perguntavam como as narrativas e imagens difundidas pelo cinema, TV, rádio e imprensa afetavam o dia a dia das pessoas comuns e, em especial, seu comportamento como consumidoras e eleitoras. 
Inspiradas na sociologia funcionalista e nas teorias da sociedade de massa, essas investigações se desenvolveram e pensaram a comunicação em um molde baseado na teoria matemática da comunicação de Shannon e Weaver, ficando conhecido mais tarde como "paradigma informacional". Nessa perspectiva, as trocas comunicativas são pensadas como um processo transmissivo no qual informações são transportadas do emissor ao receptor. Marcada por uma compreensão linear do fenômeno comunicativo, essa abordagem pensa a comunicação sobretudo sob o ponto de vista da eficácia². Ao mesmo tempo, ligado à noção de "massa", o receptor é percebido frequentemente como ator incapaz de opor resistência aos conteúdos que Ihes são oferecidos. Nesse contexto, a ideia de manipulação ideológica aparece como uma referência comumente associada ao papel desempenhado pela mídia, percebida como onipotente, em face de audiências tidas como atomizadas e apáticas.

Ao longo do século XX, no entanto, o campo de pesquisa em comunicação passa a ser irrigado por contribuições conceituais das mais diversas áreas, que complexificam o conceito de interação e redimensionam o entendimento sobre as práticas comunicativas. A comunicação passa a ser percebida em viés menos mecânico e atenção renovada é concedida à globalidade do processo dialógico instaurado entre os diferentes sujeitos na vida social.

Como nos lembra Winkin (1998), destaca-se o grupo de pesquisadores do Colégio Invisível ${ }^{3}$, que pensava a comunicação a partir de um modelo orquestral, em oposição ao informacional - por eles chamado de telegráfico, já que a comunicação, aos moldes de um telégrafo, é considerada algo transmissível de uma fonte emissora a outra receptora. A analogia da orquestra, por outro lado, enfatiza que a comunicação é um todo integrado, em que o indivíduo não é a origem (emissor) ou o fim (receptor). Ao contrário, cada sujeito participa da comunicação, integra esse processo complexo, que não pode ser reduzido a poucas variáveis lineares, com começo, meio e fim.

Os pesquisadores do Colégio Invisível estavam interessados em compreender os códigos que regem o comportamento humano como esse corpo de regras é instituído, selecionado e apreendido pelos sujeitos - em certa cultura. 0 comportamento pessoal e interpessoal, para eles, seria organizado por esses códigos, responsáveis por fomentar a significação pelo homem, a partir de contextos específicos - daí a ideia de que "todo homem viveria necessariamente (embora inconscientemente) em e por códigos, pois todo comportamento implica o seu uso" (Winkin, 1998, p. 31).

Já a partir dos anos 1980, outro autor que tem analisado as limitações da matriz paradigmática informacional e transmissiva da comunicação, chamada por ele de epistemológica, é Louis Quéré (2018), que propõe uma abordagem denominada como modelo praxeológico de comunicação. A base do modelo praxeológico é a ideia de que a comunicação é a constituição de um mundo comum pela ação reciprocamente referenciada. Para o autor, enquanto o paradigma epistemológico é fundamentado num esquema de representação, o praxeológico é fundamentado na perspectiva construcionista, em um "esquema da constituição de um mundo comum pela ação, ou, como se diz às vezes em ciências sociais, do esquema da 'construção social da realidade'" (Quéré, 2018, p. 3).

No modelo informacional ou epistemológico, a comunicação é um processo de representação de um mundo dado e predefinido cujas "propriedades são independentes da percepção e da atividade cognitiva dos sujeitos do conhecimento, que se contentam em recuperar ou em reconstituir uma realidade extrínseca" (Quéré, 2018, p.4). Ou seja, nessa perspectiva, a comunicação tem um papel instrumental e mecanicista de transmissão de informação, em que

2 Seriam eficazes os processos comunicativos nos quais o emissor consegue produzir, no receptor, as representações mentais pretendidas

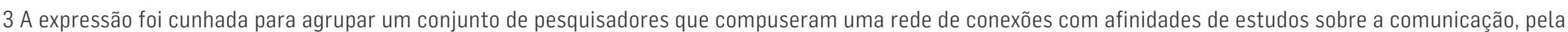

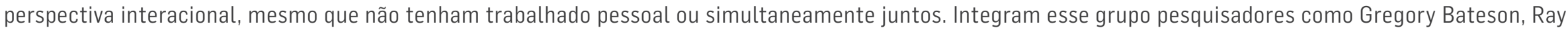
Birdwhistell, Edward Hall, Erving Goffman, Don Bateson e Paul Watzlawick. 
os sujeitos, as intenções e sobretudo os conteúdos, sob a forma de mensagens, estão dados; as representações ganham uma objetividade ou positividade prévia e autônoma, e a comunicação refere-se ao momento de seu transporte - sendo que ela é bem sucedida quando consegue reproduzir representações similares no receptor. (França, 2007, p.4)

Já no modelo praxeológico, a natureza da comunicação não é representação e sim constituição, ou seja, a comunicação é elemento fundante da experiência humana em sociedade. Neste sentido, o papel da comunicação é o de construir o mundo dos seres humanos através de sua vivência no mundo - pela comunicação, os homens se constroem, constroem seu mundo, se organizam e organizam suas experiências no mundo. A comunicação torna-se, então, uma questão de "modelagem mútua de um mundo comum em meio a uma ação conjugada" (Quéré, 2018).

\begin{abstract}
A ideia fundamental aqui presente é que a comunicação deve ser entendida como atividade conjunta de construção de uma perspectiva comum, de um ponto de vista partilhado, como base de inferência e de ação, e não mais como um processo no qual os estados intencionais são previamente providos de suas determinações, no qual os fatos e as hipóteses (representações de um mundo real predefinido) tornam-se mutuamente manifestos. Em particular, essa perspectiva comum permite aos parceiros especificar o modo pelo qual se relacionam temporariamente uns com os outros e com o mundo. Ao mesmo tempo, ela lhes permite construir, de maneira coordenada e de acordo com o modo do "sentido encarnado", aquilo que torna mutuamnete manifesto ou sensível na interação. [...] Então, para o modelo praxiológico, a comunicação é essencialmente um processo de organização de perspectivas compartilhadas, sem o qual nenhuma ação e interação se tornam possíveis. (Quéré, 2018, p.24-25)
\end{abstract}

Quanto à natureza dos sujeitos, o modelo informacional adota a noção de que a comunicação se processa entre sujeitos monológicos, que apenas se relacionam com os outros e com o mundo através da observação e da objetivação. Esse sujeito comunicar-se-ia com outros por meio da produção, validação, transmissão e inferência de representações (Quéré, 2018). Já o sujeito praxeológico se constrói a partir da relação que estabelece com o outro, sendo considerado "um sujeito dialógico que fala não apenas para o outro, mas com o outro" (França, 2007, p.4).

No que se refere ao papel da linguagem, esta se constitui elemento fundamental para a análise da comunicação, seja na perspectiva informacional ou na praxeológica. No entanto, se de um lado, no modelo informacional, a linguagem é tida como um sistema de representação do mundo e, desta forma, um sistema externo a ele ${ }^{4}$, de outro, no modelo praxeológico, é elemento de expressão e constituição, na medida em que possibilita objetivação da subjetividade dos sujeitos e que marca sua presença no mundo. É pela linguagem que o ser humano interage consigo e com os outros.

Sobre a relação que os paradigmas informacional e praxeológico estabelecem entre comunicação e vida social, o informacional separa a comunicação como um processo independente da sociedade e o praxeológico entende a comunicação como constituinte dela. Nessa perspectiva, a priori, a comunicação ou o mundo social representado por ela não existem, são antes dimensões de um mesmo fenômeno. "Por esse caminho, a comunicação deixa de ser um processo recortado e restrito, e é tomada como lugar de constituição dos fenômenos sociais, atividade organizante da subjetividade dos homens e da objetividade do mundo" (França, 2007, p.6). Para Quéré (2018, p.23),

A tematização que nos interessa segue o caminho oposto do esquema "epistemológico". Ela não trata a objetividade do mundo e a subjetividade dos agentes (isto é, sua interioridade e, ao mesmo tempo, seu estatuto de sujeito autônomo e responsável) como dados; ela as relaciona a uma "atividade organizante", mediada de modo simbólico, efetuada conjuntamente pelos membros de uma comunidade de linguagem e de ação no quadro da coordenação de suas ações práticas.

4 França e Maia (2003, p. 5) chamam a atenção para o dualismo dessa acepção, que corresponde a uma "concepção indicial da comunicação: os indivíduos produzem e interpretam índices; a recepção da comunicação consiste em inferir as intenções e informações transmitidas". 
Em seu conjunto, a apresentação do desenvolvimento das teorias da comunicação traz elementos que permitem questionar os pressupostos da noção de transferência de conhecimento nas organizações, se entendemos conhecimento como construção que se realiza em processos de comunicação - não algo que se representa (e transmite), mas algo instituidor das relações sociais, dos sujeitos e das organizações.

\section{DISCUSSÃO CRÍTICA}

Para desenvolver as reflexões propostas, realizou-se um levantamento bibliográfico sobre as teorias da comunicação para construir um referencial teórico que ressaltasse pontos relevantes sobre o tema da transferência do conhecimento. Assim, o estudo propõe uma análise qualitativa e interpretativa, inspirada na análise crítica do discurso, desconstruindo a transferência de conhecimento enquanto prática que toma o ser humano e o conhecimento como coisas, bem como as implicações decorridas dessas premissas.

\section{A análise crítica do discurso}

A Análise Crítica do Discurso (ACD), a partir dos trabalhos de Fairclough (2001, 2003), Chouliaraki e Fairclough (1999) e Wodak e Meyer (2009), evidencia o discurso não como uma construção meramente textual, mas algo que revela complexa relação com o contexto e com estruturas sociais mais amplas. 0 discurso, nessa perspectiva, é não somente um modo de representação, mas também de ação, uma forma com que "as pessoas podem agir sobre o mundo e especialmente sobre os outros" (Fairclough, 2001, p.90).

Essa escolha metodológica ratifica nosso entendimento da comunicação como espaço de constituição da vida coletiva e 0 entendimento de que as mudanças organizacionais e sociais são subsidiadas por práticas discursivas, de modo que transformações discursivas podem ser consideradas um caminho para transformações ou cristalizações culturais, organizacionais e sociais. Nas palavras de Fairclough (2001, p.28), "as hegemonias em organizações e instituições particulares, e no nível societário, são produzidas, reproduzidas, contestadas e transformadas no discurso". De modo que todo processo de mudança social (e organizacional, por óbvio) também se deixa ver pelas práticas discursivas que o viabiliza ou dificulta.

\footnotetext{
Há muitos exemplos de mudança: mudança nas relações entre médicos e pacientes, entre políticos e o público, entre mulheres e homens no local de trabalho e na família, todas elas parcialmente constituídas por novas práticas discursivas. Além disso, 0 destaque cada vez maior do discurso nas transformações sociais relaciona-se, como sugeri anteriormente, com uma preocupação para controlar o discurso: causar mudanças nas práticas discursivas como parte da engenharia da mudança social e cultural. Estamos observando uma "tecnologização do discurso", em que tecnologias discursivas, um tipo de "tecnologias de governo" [...], são sistematicamente aplicadas em uma variedade de organizações por tecnólogos profissionais que pesquisam, redesenham e fornecem treinamento em práticas discursivas. (Fairclough, 2001, p. 26)
}

O uso instrumental da tecnologização do discurso para causar mudanças socioculturais parece ir ao encontro da perspectiva até aqui colocada: contando com o aparato simbólico dos sistemas de gestão, temos um corpo profissional que, ao inserir a pauta da transferência do conhecimento como possibilidade de aumentar 0 ativo intangível das organizações, reafirma e propaga pontos de vista ideologicamente orientados e instaura renovadas práticas discursivas sobre a constituição das relações organizacionais.

A análise das práticas discursivas, na perspectiva da ACD, relaciona dialeticamente a análise textual e a análise da prática social. Por isso, os objetos de investigação ultrapassam o texto (ou a análise textual), sem dele prescindir, incorporando sua 
relação com estruturas sociais mais amplas, que conformam sua produção, e com os processos sociais por meio dos quais os indivíduos constroem sentido em suas interações - através daqueles textos. Ou seja, a análise dos textos é sempre uma análise em relação, uma relação dialética com as práticas discursivas e sociais.

A partir desse entendimento, Fairclough (2001, p. 22) propõe um modelo tridimensional de análise, em que relaciona texto, discurso e prática social e pondera que "qualquer 'evento' discursivo (isto é, qualquer evento de discurso) é considerado como simultaneamente um texto, um exemplo de prática discursiva e um exemplo de prática social", contribuindo para construir tanto as identidades sociais (as posições de sujeito para os sujeitos sociais) quanto as relações sociais e os sistemas de conhecimento e crença. Essa concepção tridimensional do discurso é representada na Figura 1:

Figura 1: Concepção tridimensional do discurso

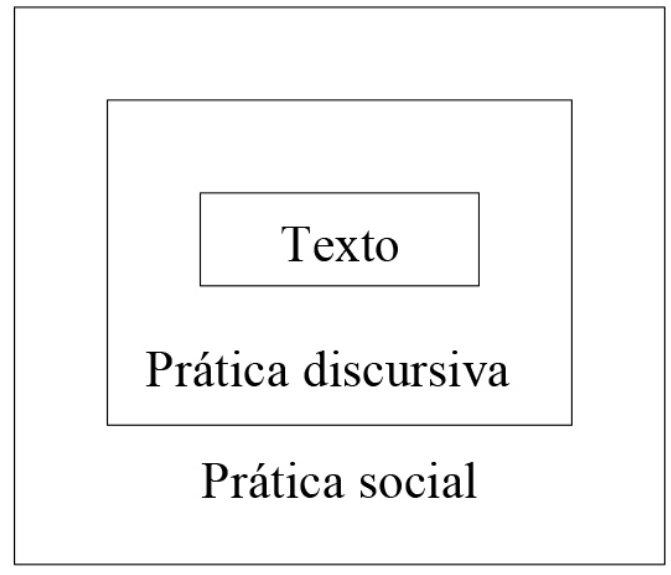

Fonte: Fairclough (2001, p.101).

Assim, fazem parte do modelo tridimensional de análise de Fairclough (2001) as três dimensões do discurso: texto, prática discursiva e prática social. Entendendo por texto qualquer instância da linguagem em uso, falada ou escrita; por prática discursiva, a interação específica em que se configuram os processos de construção de sentidos entre os interlocutores (relaciona-se, pois aos processos de produção, distribuição e consumo textual); e por prática social, a dimensão social mais ampla (recortada em aspectos econômicos, políticos e institucionais particulares) em que o discurso é gerado.

Em nossa análise, interessa-nos a abordagem da prática social que se fundamenta na relação do discurso com a ideologia e hegemonia. Na perspectiva da ideologia, a ACD preocupa-se com aspectos textuais investidos ideologicamente (principalmente os sentidos das palavras, as pressuposições, as metáforas e os estilos) e, na perspectiva da hegemonia, preocupa-se com as orientações econômicas, políticas, ideológicas e culturais das práticas sociais. Merece atenção o que Fairclough (2001, p.117) entende como ideologias:

significações/construções da realidade (o mundo físico, as relações sociais, as identidades sociais) que são construídas em várias dimensões das formas/sentidos das práticas discursivas e que contribuem para a produção, a reprodução ou a transformação das relações de dominação.

Nesse sentido, quanto mais as ideologias embutidas nas práticas discursivas se tornam naturalizadas e adquirem o status de senso comum, mais são eficazes, cabendo ao analista crítico do discurso justamente o papel de revelar tais posições para que os sujeitos possam agir sobre a realidade social. Ou seja, para o autor, a ideologia está tanto nas estruturas (ordens do discurso) quanto nos eventos discursivos (no modo como os sujeitos são posicionados ideologicamente), e a intervenção do analista do discurso, revelando as ideologias embutidas, pode contribuir para que os interlocutores ajam criativamente e reestruturem suas práticas sociais. 
Além disso, a prática discursiva, a produção, a distribuição e o consumo (como também a interpretação) de textos são uma faceta da luta hegemônica que contribui em graus variados para a reprodução ou a transformação não apenas da ordem de discurso existente [...] mas também das relações sociais e assimétricas existentes. (Fairclough, 2001, p. 123-124)

Para o autor, cada uma das dimensões do discurso - texto, prática discursiva e prática social - se refere a uma das "três funções da linguagem e a dimensões de sentido que coexistem e interagem em todo discurso" (Fairclough, 2001, p. 92): a função identitária (os modos de construção das identidades sociais no discurso); a relacional (os modos de negociação e representação das relações sociais dos interlocutores no discurso); e a ideacional (os processos de construção de sentido a partir dos textos, ou seja, os modos pelos quais "significam o mundo e seus processos, entidades e relações" (Fairclough, 2001, p. 92)).

\section{AS TEORIAS DA COMUNICAÇÃO, A ANÁLISE CRÍTICA DO DISCURSO E A TRANSFERÊNCIA DO CONHECIMENTO NAS ORGANIZAÇÕES}

0 desenvolvimento das teorias da comunicação, como apresentado, parecem fornecer pistas importantes para problematizar a noção de transferência do conhecimento nas organizações. Em primeiro lugar, o modelo informacional, baseado na lógica transmissiva de conteúdo, mostra-se limitado para abarcar a complexidade das relações sociais e dos processos de significação que fundamentam a comunicação, além de considerar o receptor como polo passivo, integrante de uma sociedade de massa. Paralelamente, a noção de transferência do conhecimento apresenta as mesmas limitações ao desconsiderar os processos de significação e comunicação que integram o processo de conhecer, reificando o conhecimento como significado, algo que os indivíduos possuem, uma coisa que pode ser transmitida a outro.

Num viés praxeológico, que considera a comunicação como construção que privilegia a autonomia dos interlocutores no processo de significação e de engendramento de sua realidade social, encontramos rastros para pensar que o conhecimento é da ordem do sentido, do porvir, uma construção que se dá na relação intersubjetiva dos sujeitos, no encontro dos sujeitos uns com os outros e com o mundo. As críticas feitas ao modelo praxeológico têm sido endereçadas principalmente à falta de uma problematização consistente sobre a dimensão do poder que pauta as relações sociais: a construção de um mundo comum pela comunicação é um processo negociado entre sujeitos que se relacionam, de modo que as assimetrias, as desigualdades e as injustiças precisariam ser pensadas como seus elementos fundamentais.

Por isso, nos parece relevante a ACD nos ensinar que, nas relações sociais, os sujeitos, como seres de linguagem e relativamente autônomos (ou seja, embora não de forma consciente e plena), possam perpetuar ou transformar sua própria realidade, a partir das práticas discursivas que revestem seus cotidianos. Assim, deve-se questionar os sentidos das palavras e a quem interessa manter naturalizada a noção de que o conhecimento é transmitido nas organizações. A nosso ver, tal perspectiva é carregada ideologicamente de uma visada gerencial que coaduna com um modelo produzido pelo capitalismo altamente perverso.

Segundo as três funções da linguagem e as dimensões de sentido do discurso propostas por Fairclough (2001), podemos dizer que a noção de transferência do conhecimento subjuga os sujeitos organizacionais, admitindo para eles a função de emissor e receptor de significados predefinidos, anulando sua potência e capacidade criativa para construir sentidos autonomamente. As relações sociais entre os interlocutores, tais como se apresentam enquanto discurso, também reforçam a assimetria entre a organização e seus sujeitos, uma vez que a prática serve aos objetivos da gestão, devendo trazer resultados de seu interesse. A função ideacional, portanto, nos parece indicar que a naturalização e propagação de estudos teóricos e de práticas pautadas na noção de transferência do conhecimento são formas silentes de perpetuar uma determinada ordem de coisas que, ao 
criar mecanismos de apropriação do que os sujeitos organizacionais constroem como conhecimento, segundo interesses organizacionais, e os mantêm em posição passiva na proposição de suas próprias pautas de interesse e construção de sentidos.

\section{DISCUSSÃO E CONCLUSÕES}

É notório que as estratégias transmissivas, verticalizadas e assimétricas ainda embasem as relações instauradas no ambiente organizacional e, nem no campo teórico nem no campo da prática, podemos considerar a suplantação de uma perspectiva instrumental por outra mais relacional. Contudo, se nos estudos e práticas de gestão organizacional, a noção de transferência do conhecimento já se encontra naturalizada, adquirindo o status de senso comum, este trabalho propõe que cabe aos estudiosos de comunicação organizacional, numa perspectiva crítica, desvelar as ideologias embutidas nas práticas discursivas que a sustentam, como modo de desestabilizar as relações de dominação das práticas organizacionais.

Há de se enfatizar que, embora se reconheça que a noção de transferência do conhecimento possa ser enriquecida com aportes teóricos da comunicação, o estudo também deixa pontuada certa fragilidade nas abordagens comunicacionais acionadas, notadamente no que se refere à forma como abordam (ou deixam de abordar) as questões de poder, ideologia e hegemonia - o que se buscou refletir a partir do cotejamento com a análise crítica do discurso.

Nesse sentido, ao tentar desnudar as relações de dominação construídas no campo simbólico e da linguagem, acredita-se que é possível fomentar a reflexão dos interlocutores sobre sua situação, posicionamentos ideológicos e relações, de modo que possam agir criativamente sobre elas, e mesmo reestruturar suas práticas sociais. Investigações desta natureza, como o esforço aqui empreendido, podem parecer estudos de menor relevância e não integrar as pautas prioritárias de estudos da área. No entanto, defendemos a importância e a necessidade de essas investigações serem tomadas como objetos de estudo relevantes na comunicação organizacional, subsidiando o desenvolvimento de aportes críticos, e não apenas epistemológicos, que reverberem também em práticas organizacionais mais justas.

\section{REFERÊNCIAS}

ALVARENGA NETO, Rivadávia Correa Drummond de. Gestão da informação e do conhecimento nas organizações: análise de casos relatados em organizações públicas e privadas. 2002. 235f. Dissertação (Mestrado em Ciência da Informação) - Escola de Ciência da Informação, Universidade Federal de Minas Gerais, Belo Horizonte, 2002.

CHIAVENATO, Idalberto. Introdução à teoria geral da administração. 7. ed. Rio de Janeiro: Elsevier, 2010.

CHOULIARAKI, Lilie; FAIRCLOUGH, Norman. Discourse in late modernity, rethinking critical discourse analysis. Edinburgh: Edinburgh University Press, 1999.

DAVENPORT, Thomas H.; PRUSAK, Laurence. Conhecimento empresarial: como as organizações gerenciam o seu capital intelectual. Rio de Janeiro: Elsevier, 2003.

DRUCKER, Peter F. The coming of the new organization. Harvard Business Review, Boston, n.66, p.45-53, jan./fev. 1988.

DUTTA, Soumitra. Strategies for implementing knowledge-based systems. IEEE Transactions on Engineering Management, New York, v. 44, n. 1, p. 79-90, fev. 1997. 
FAIRCLOUGH, Norman. Discurso e mudança social. Brasília, DF: Editora UnB, 2001.

Analysing discourse: textual analysis for social research. New York: Routledge, 2003.

FRANÇA, Vera V.; MAIA, Rousiley. A comunicação e a conformação de uma abordagem comunicacional dos fenômenos. In: LOPES, Maria Immacolata V. (Org.). Epistemologia da comunicação. São Paulo: Loyola, 2003. p.187-203.

FRANÇA, Vera V. Contribuições de G. H. Mead para pensar a comunicação. In: ENCONTRO DA COMPÓS, 16., 2007, Curitiba. Anais... Curitiba: UTP, 2007. 1 CD-ROM.

GOMEZ, Maria Nélida González de. A representação do conhecimento e o conhecimento da representação: algumas questões epistemológicas. Ciência da Informação, Brasília, DF, v. 22, n. 3, p. 217-222, set./dez. 1993.

LAVILLE, Christian; DIONNE, Jean. A construção do saber. manual de metodologia da pesquisa em ciências humanas. Porto Alegre: Artmed; Belo Horizonte: Editora UFMG, 1999.

MARSHALL, Lucy. Facilitating knowledge management and knowledge sharing: new opportunities for information professionals. Online, Wilton, v. 21, n. 5, p. 92-98, 1997.

QUÉRÉ, Louis. De um modelo epistemológico da comunicação a um modelo praxiológico. In: FRANÇA, Vera Veiga; SIMÕES, Paula. O modelo praxiológico e os desafios da pesquisa em comunicação. Porto Alegre: Sulina, 2018. p. 15-48.

QUINN, James Brian; BARUCH, Jordan J.; ZIEN, Karen Anne. Innovation explosion: using intellect and software to revolutionize growth strategies. New York: Free Press, 1997.

WINKIN, Yves. A nova comunicação: da teoria ao trabalho de campo. Campinas: Papirus, 1998.

WODAK, Ruth; MEYER, Michael (ed). Methods of critical discourse analysis. London: Sage Publications, 2009

Texto recebido em 07/04/2018 e aprovado em 01/06/2018. 